\title{
The Relationship of Proinflammatory and Antiinflammatory Adipokines in the Development of Metabolic Syndrome in Centrally Obese Men
}

\author{
Anna Meiliana ${ }^{1,2^{*}}$, Andi Wijaya $^{1,2}$, Suryani As'ad ${ }^{1}$
}

${ }^{1}$ Hasanuddin University, Indonesia

${ }^{2}$ Prodia Clinical Laboratory, Indonesia

\section{Abstract}

$\mathrm{B}$ ACKGROUND: The increased prevalence of obesity worldwide is correlated with increasing prevalence of metabolic syndrome. Studies of adipose tissue have been improved from an inert energy storage to a metabolic active endocrine organ. Adipokines secreted by this tissue play a role in maintaining metabolic homeostasis. The large mass of visceral fat tissue causing the imbalance of these adipokines leading to metabolic abnormality known as the metabolic syndrome (MetS). This study was performed to understand relationship of proinflammatory adipokines (resistin, TNF- $\alpha$, RBP4 and visfatin) and anti-inflammatory adipokines (adiponectin and vaspin) in the development of MetS.

METHODS: This was a cross-sectional study using 122 central obesity men with waist circumference $>90 \mathrm{~cm}$, age from $30-60$ years old. Proinflammatory adipokines (resistin, TNF- $\alpha$, RBP4 and visfatin) and anti-inflammatory adipokines (adiponectin and vaspin) was measured by ELISA method.

RESULTS: The crosstab study showed that subjects who have $>2$ high proinflammatory adipokines $(17.3 \%)$ has higher MetS prevalence $(\mathrm{OR}=1.16 ; \mathrm{p}=0,72)$ compare to subjects with $<2$ high proinflammatory adipokines $(14.8 \%)$, subjects with low anti-inflammatory adipokines profile $(18.9 \%)$ has higher prevalence of $\mathrm{MetS}(\mathrm{OR}=1.38$; $\mathrm{p}=0,22$ ) compare to subjects with high anti-inflammatory adipokines $(13.7 \%)$, and the prevalence of MetS became 1.49 times higher $(\mathrm{p}=0,24)$ when we combine the high RBP4 and low adiponectin profile $(21.1 \%)$ compare to subjects with low RBP4 and high adiponectin (14\%).

CONCLUSIONS: This study showed that each adipokine was not strong enough to induce MetS, so the interaction between proinflammatory and antiinflammatory adipokines were needed to induce a systemic metabolic abnormality. Thus, the adipokines equilibrium was important to prevent MetS especially in centrally obese subjects.

KEYWORDS: Obesity, Metabolic Syndrome, Adipokines, Resistin, TNF- $\alpha$, RBP4, visfatin, adiponectin, vaspin.

\section{Introduction}

Obesity, as the result of the combination of genetic factors with a sedentary life style has become a great disease burden worldwide $(1,2)$. Fat accumulation in obese individuals, especially in those with visceral obesity, has been related with many chronic metabolic disorders characterized by abnormal cytokine production, increased acute-phase reactants and other mediators, and activation of a network 
of inflammatory signaling pathways $(3,4)$.

Adipocyte has an important role in regulating energy homeostasis and many physiologic pathways (5). Many bioactive substances (referred to as "adipocytokines" or "adipokines") secreted from the adipose tissue, such as leptin, TNF- $\alpha$, IL- 6 , PAI-1, adiponectin, resistin, angiotensinogen and MCP-1 can contribute in physiologic function $(6,7)$.

International Diabetes Federation (IDF) has defined the criteria for Metabolic Syndrome (MetS) that patient must have central obesity, with waist circumference > $90 \mathrm{~cm}$ for Asian men, plus any two of the following four factors: TG level $\geq 150 \mathrm{mg} / \mathrm{dL}(1.7 \mathrm{mmol} / \mathrm{L})$ or specific treatment for this lipid abnormality; HDL cholesterol: Men $<40 \mathrm{mg} / \mathrm{dL}(1.03 \mathrm{mmol} / \mathrm{L})$ Women $<50 \mathrm{mg} / \mathrm{dL}(1.29$ $\mathrm{mmol} / \mathrm{L}$ ) or specific treatment for this lipid abnormality; Blood pressure: systolic $\mathrm{BP} \geq 130$ or diastolic $\mathrm{BP} \geq 85$ $\mathrm{mmHg}$, or treatment of previously diagnosed hypertension; Fasting plasma glucose (FPG) $\geq 100 \mathrm{mg} / \mathrm{dL}(5.6 \mathrm{mmol} / \mathrm{L})$, or previously diagnosed type 2 diabetes $(3,8)$.

Resistin and TNF- $\alpha$ which have a potential proinflammatory properties, by triggering cytokine production and NF-K $\beta$ activation, and finally induced the vascular disease and insulin resistance $(9,10)$.
Studies showed that RBP4 overexpression can induce insulin resistace. Other data showed that RBP4 level was positively correlated to MetS components and negatively correlated to adiponectin level. These, given a possibility that RBP4 is not directly involved in the development of insulin resistance in humans but is expressed in response to other phenomena associated with the insulin resistance syndrome, associated with adipose tissue inflammation $(11,12,13)$.

Adiponectin play an important role as an antiinflammatory proteins by inhibiting TNF- $\alpha$ via a NF- $x \beta$ pathway (14).

Vaspin (visceral adipose tissue-derived serpin) is a member of serine protease inhibitor (serpin) superfamily and is produced in the visceral adipose tissue. The level of Vaspin increases at the peak of obesity and insulin resistance, but decreases with the worsening of diabetes. Vaspin treatment to WAT as the main target of vaspin suppresses the expression of leptin, resistin, and TNF- $\alpha$, whereas it increases that of the glucose transporter- 4 and adiponectin (15), and shows the anti-inflammatory role of vaspin, suggesting that vaspin represents a new biomarker for obesity and MetS (16).

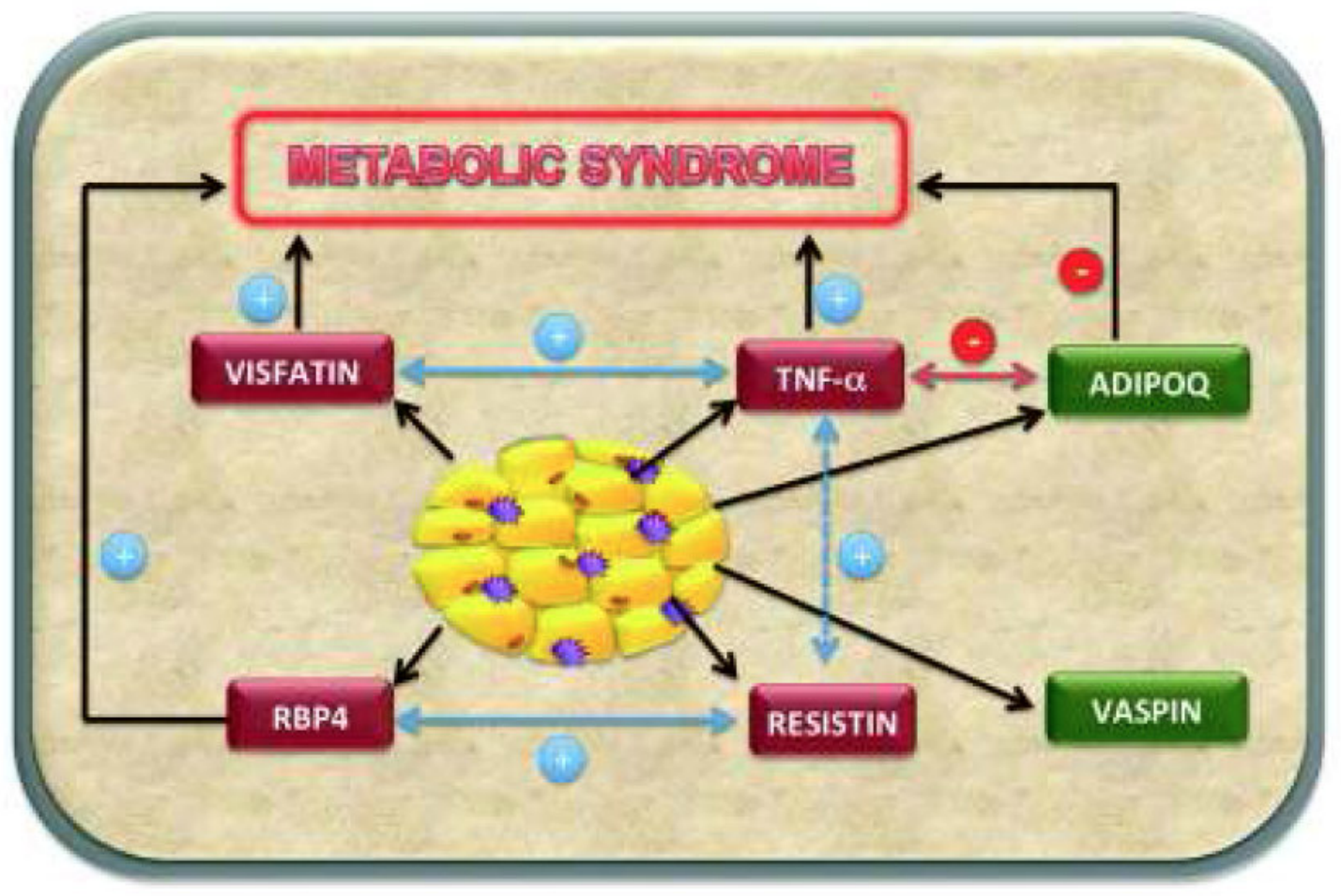

Figure 1. Model of Correlation between Pro- and Antiinflammatory Adipokines to MetS. 
Visfatin is a recently discovered adipokine produced and secreted primarily by visceral WAT. Visfatin binds to and activates the insulin receptor on a different site with insulin, exerting insulin-mimetic effects both in vitro and in vivo (17).

Excess visceral fat can lead to metabolism abnormality due to secretion inbalance of adipokines. Therefore, a study on the relation of adipokines equilibrium with impaired metabolism (MetS) is worthwhile in order that we can formulate the preventive strategies especially for the obese individuals. In figure 1 we tried to summarize the interaction between pro- and anti-inflammatory adipokines, and their effects to induce MetS.

This study was performed to understand the relationship of proinflammatory adipokines (resistin, TNF- $\alpha$, RBP4 and visfatin) and anti-inflammatory adipokines (adiponectin and vaspin) in the development of metabolic syndrome in male subjects with central obesity.

\section{Methods}

This was a cross-sectional study using 122 centrally obese men with waist circumference $>90 \mathrm{~cm}$, aged 30-60 years old, and agreed to participate in the study by signing an informed consent. Subjects were recruited from PT Showa Indonesia, Cikarang, Indonesia. 180 subjects were participated, but only 122 subjects were eligible due to inclusion and exclusion criterias.

Subjects with fasting plasma glucose $>126 \mathrm{mg} / \mathrm{dL}$, GFR $<60 \%, \mathrm{ALT} / \mathrm{AST}>2 \times$ reference value, consuming anti-inflammatory agents in the last 3 months, and/or with hsCRP $>10 \mathrm{mg} / \mathrm{L}$ were excluded to prevent the hormonal and pathologic bias of inflammatory - related adipokines level.

Resistin (R\&D Quantikine ${ }^{\circledR}$ cat \# DRSN00), TNF- $\alpha$ (R\&D Quantikine ${ }^{\circledR}$ cat \# DTA00C), adiponectin (Daiichi ${ }^{\circledR}$ cat \# 975506-001), RBP4 (R\&D Quantikine ${ }^{\circledR}$ cat \# DRB400), visfatin (Adipogen ${ }^{\circledR}$ cat \# V0623TP), and vaspin (Adipogen ${ }^{\circledR}$ cat \# V0712EK) was performed by ELISA methods (Microplate Reader 680 series Bio-Rad Laboratories, Inc., Hercules, CA 94547, USA) in Prodia Laboratory, Jakarta.

The data then analyzed using SPSS for windows ver. 16.00 (USA, SPSS Inc., 1989-2008). The significancy level used was $5 \%$. Univariate descriptive analysys was performed to observe the mean, minimum, maximun and standard deviation of the data after checking the normal distribution test. To find the correlation and the differentiation, Pearson and Spearman correlation test and student t-test was performed. At last, we did the crosstabulation analysis to observe the increasing or decreasing trend of adipokines related to MetS prevalency in this study population.

\section{Results \& Discussions}

\section{Subjects characteristics}

Table 1 shows that all 122 subjects had met the study's inclusion criteria. WC was found to be significantly correlated to body weight, according to the increased visceral fat mass. WC was also found to be correlated significantly with hsCRP $(\mathrm{p}<0,01)$ and HOMA IR $(\mathrm{p}<0,01)$, showing that increased visceral fat is related to higher risk for inflammation and insulin resistance.

\section{Relationship between each adipokines and MetS}

Adipose tissue is now recognized as a highly active metabolic and endocrine organ. Great strides have been made in uncovering the multiple functions of the adipocyte in both cellular and molecular detail, but it is essential to remember that adipose tissue normally operates as a structured whole. Attempting to understand how all these factors converge and regulate adipose tissue function is a prime example of integrative physiology because adipose tissue metabolism is extremely dynamic. This implies the existence of one or more signals to the adipose tissue that reflect the body's energy status, and points out again the need for an integrative view on the adipose tissue function (18).

We didn't find any significant correlation between each adipokine to MetS, so a cross tabulation analysis in Figure 2 was performed to analyze the trends of each adipokine in increasing the risk of MetS.

From the crosstabulation analysis, we found that among other adipokines, RBP4 showed the strongest impact to MetS (Fig. 2), where MetS was found to be higher in subjects with higher RBP4 levels. Inversely, subjects with higher adiponectin levels seemed to reduce the risk of MetS. 
Table 1. Subjects' Clinical and Biochemical Characteristics

\begin{tabular}{|c|c|c|c|c|}
\hline Parameters & Unit & Min & Max & $x \pm S D$ \\
\hline Age & Year & 30,00 & 53,00 & $38,12 \pm 5,48$ \\
\hline \multicolumn{5}{|l|}{ Clinical } \\
\hline WC & $\mathrm{cm}$ & 91,00 & 126,00 & $97,67 \pm 5,14$ \\
\hline SBP & $\mathrm{mmHg}$ & 90,00 & 150,00 & $114,55 \pm 13,24$ \\
\hline DBP & $\mathrm{mmHg}$ & 60,00 & 110,00 & $76,15 \pm 10,16$ \\
\hline \multicolumn{5}{|l|}{ Biochemical } \\
\hline FPG & $\mathrm{mg} / \mathrm{dL}$ & 70,00 & 119,00 & $87,78 \pm 8,86$ \\
\hline $\mathrm{HDL}$ & $\mathrm{mg} / \mathrm{dL}$ & 29,00 & 71,00 & $44,36 \pm 7,74$ \\
\hline TG & $\mathrm{mg} / \mathrm{dL}$ & 42,00 & 1312,00 & $196,12 \pm 136,78$ \\
\hline LDL & $\mathrm{mg} / \mathrm{dL}$ & 39,00 & 313,00 & $138,82 \pm 37,32$ \\
\hline AST & $\mathrm{U} / \mathrm{L}$ & 11,00 & 90,00 & $39,67 \pm 16,89$ \\
\hline ALT & $\mathrm{U} / \mathrm{L}$ & 17,00 & 60,00 & $30,04 \pm 9,28$ \\
\hline Bilirubin & $\mathrm{mg} / \mathrm{dL}$ & 0,07 & 0,42 & $0,23 \pm 0,07$ \\
\hline GFR & $\mathrm{mL} / \mathrm{min} / 1.73 \mathrm{~m}^{2}$ & 60,95 & 168,14 & $83,10 \pm 16,23$ \\
\hline HOMA IR & - & 0,52 & 16,64 & $2,24 \pm 2,01$ \\
\hline hsCRP & $\mathrm{mg} / \mathrm{L}$ & 0,24 & 9,12 & $2,33 \pm 1,82$ \\
\hline \multicolumn{5}{|c|}{ Proinflammatory Adipokines } \\
\hline Resistin & $\mathrm{ng} / \mathrm{mL}$ & 0,67 & 23,38 & $8,95 \pm 5,33$ \\
\hline TNF- $\alpha$ & $\mathrm{ng} / \mathrm{mL}$ & 1,33 & 8,43 & $2,81 \pm 1,12$ \\
\hline RBP4 & $\mathrm{ng} / \mathrm{mL}$ & 25900 & 91700 & $53318 \pm 13297$ \\
\hline Visfatin & $\mathrm{ng} / \mathrm{mL}$ & 0,06 & 8,44 & $1,70 \pm 1,40$ \\
\hline \multicolumn{5}{|c|}{ Antiinflammatory Adipokines } \\
\hline Adiponectin & $\mathrm{ng} / \mathrm{mL}$ & 831,69 & 5495,79 & $3015,71 \pm 1959,93$ \\
\hline Vaspin & $\mathrm{ng} / \mathrm{mL}$ & 0,00 & 11,04 & $2,42 \pm 3,99$ \\
\hline
\end{tabular}

Notes: $\mathrm{WC}=$ Waist Circumference; SBP = Systolic Blood Pressure; DBP = Diastolic Blood Pressure; FPG = Fasting Plasma Glucose; HDL = High Density Lipoprotein Cholesterol; TG = Triglyceride; LDL = Low Density Lipoprotein Cholesterol; AST = Aspartate Aminotransferase; ALT = Alanine Aminotransferase; GFR = Glomerular Filtration Rate; HOMA IR = Homeostasis Model Assessment of Insulin Resistance; hsCRP = High Sensitivity C - Reactive Protein; TNF- $\alpha=$ Tumor Necrosis Factor $\alpha$; RBP4 = Retinol Binding Protein 4. 


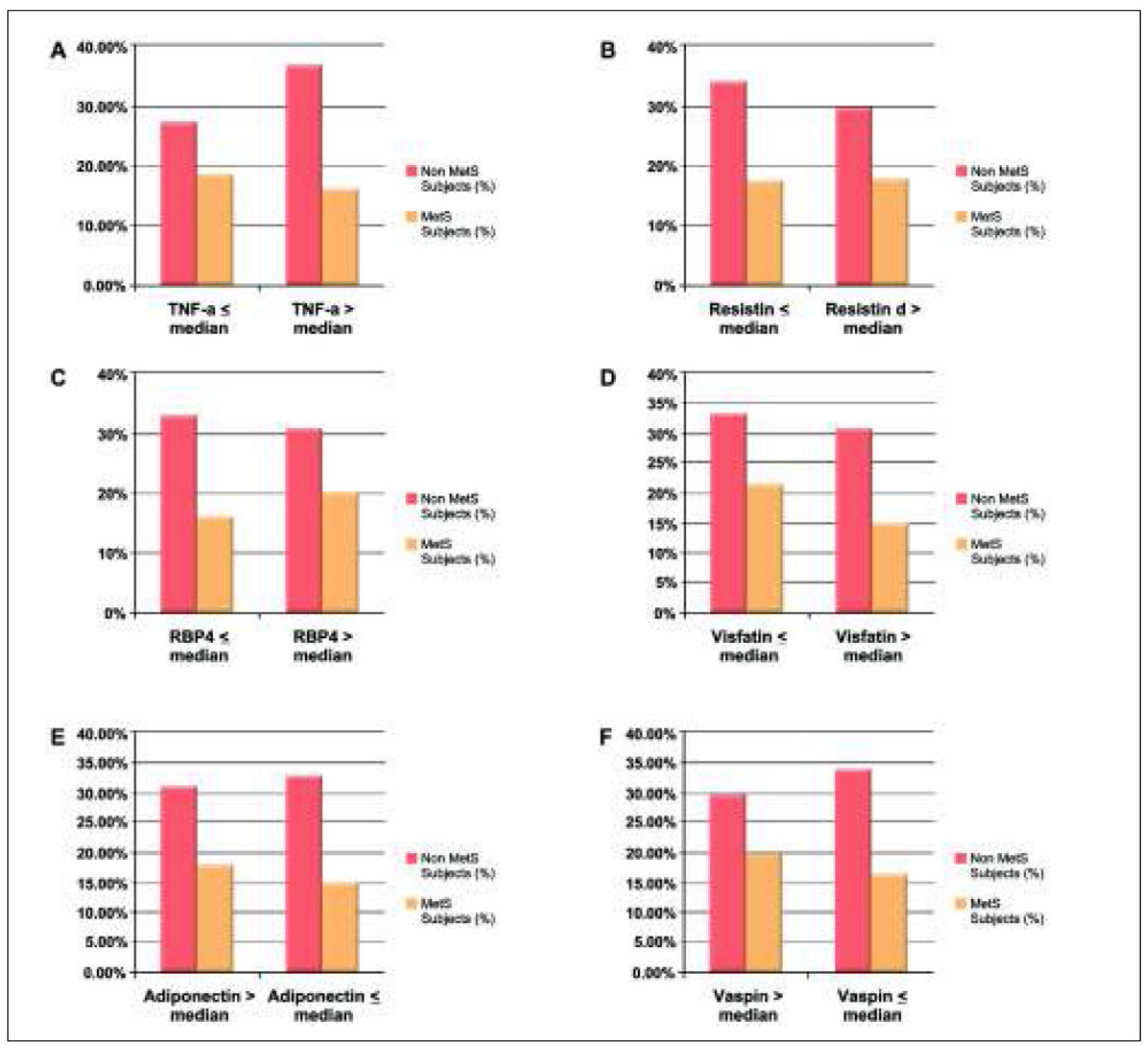

Figure 2. The Prevalence of Mets by Levels of Adipokines.

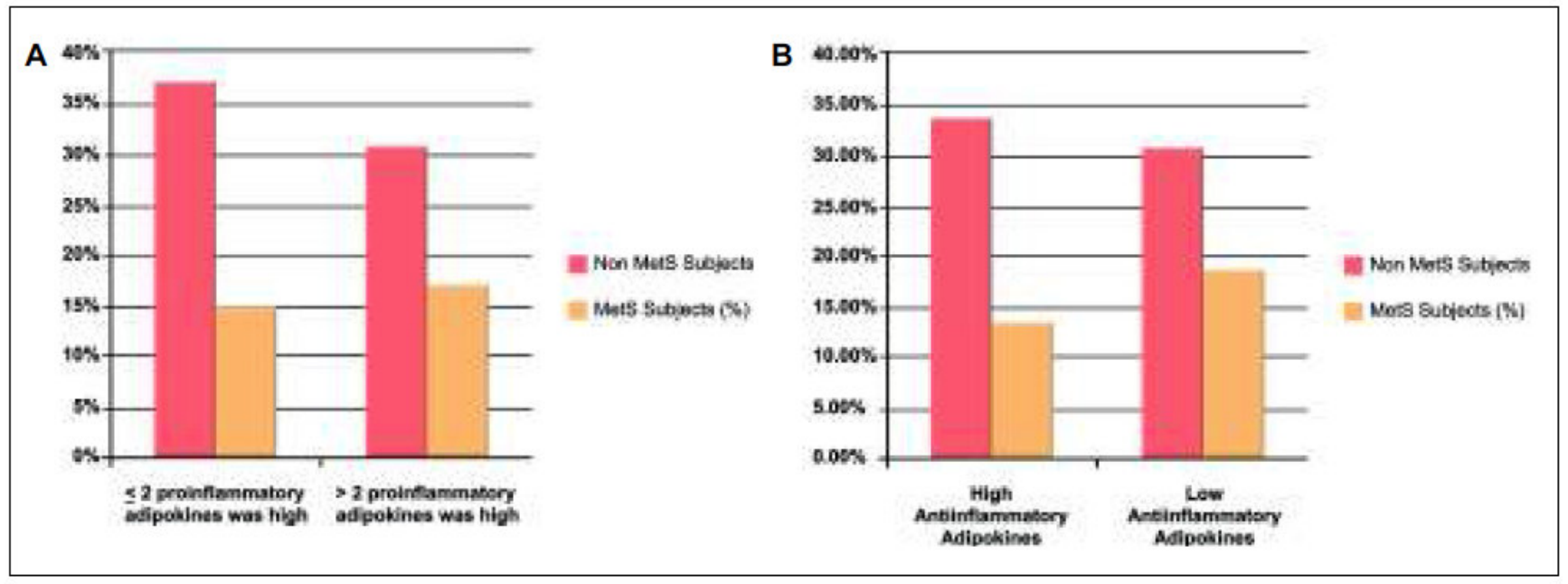

Figure 3. (A) The Prevalence of Mets by Levels of Proinflammatory Adipokines.

(B) The Prevalence of Mets by Levels of Antiinflammatory Adipokines. 


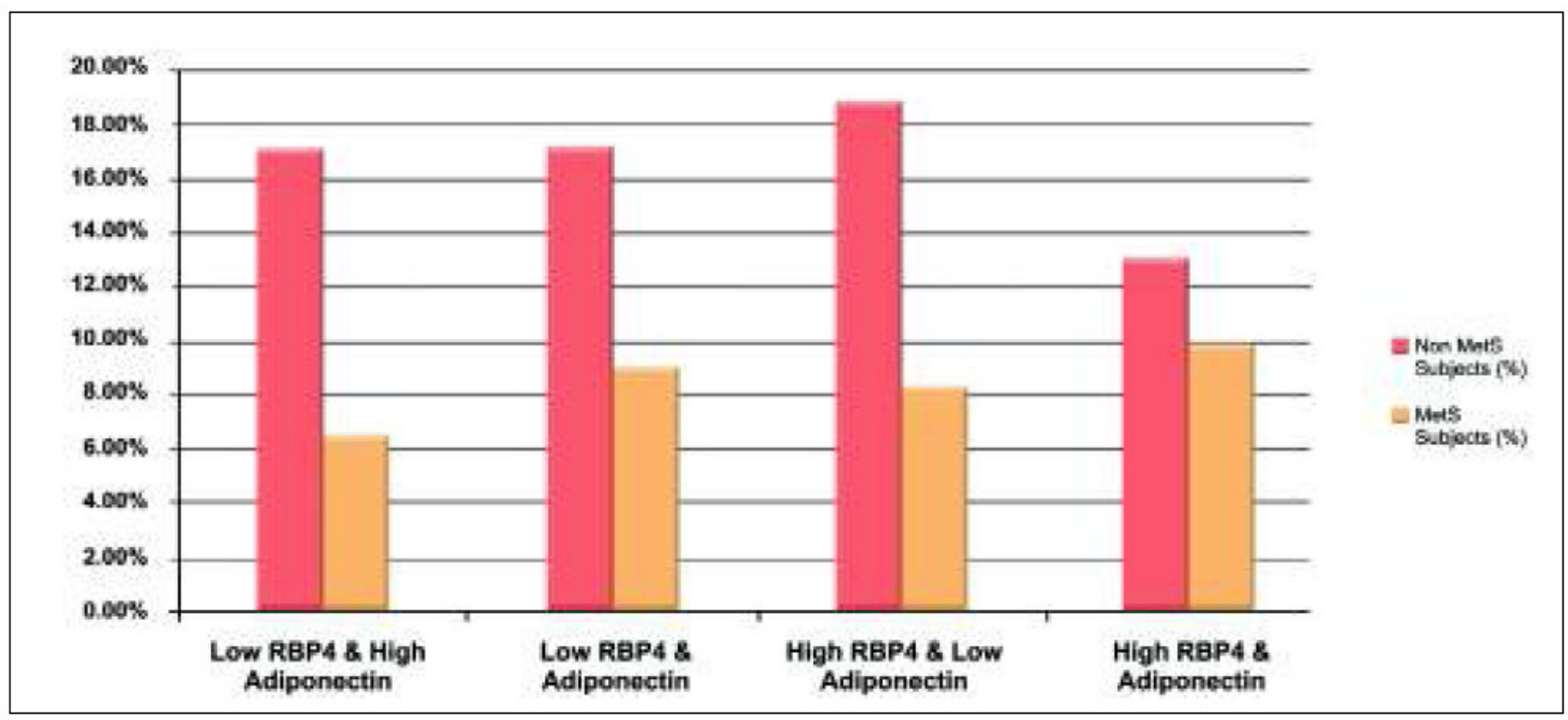

Figure 4. The Prevalence of Mets by Levels of Combination RBP4 and Adiponectin. (Group $1=$ Low RBP4 \& High Adiponectin; Group $2=$ Low RBP4 \& Adiponectin; Group 3 = High RBP4 and Low Adiponectin; Group 4 = High RBP4 \& Adiponectin).

\section{Analysis of adipokines combination to MetS}

Different from in vitro treatment, in vivo cytokine action results from a complex interplay between networks of pro- and anti-inflammatory cytokines through a coordinate regulation role of anti-inflammatory cytokines to the proinflammatory cytokines action (19). Thus, we tried to analyze the combination of proinflammatory, antiinflammatory and both adipokines (Figure 3 and 4).

The combination of proinflammatory adipokines showed that subjects who have $>2$ high (adipokines level higher than median) proinfla mmatory adipokines (17.3\%) has no different significantly of MetS prevalence $(\mathrm{OR}=1.16 ; \mathrm{p}=0,72)$ compare to subjects with $<2$ high proinflammatory adipokines (14.8\%) (Figure 3A).

The crosstabulation analysis between antiinflammatory adipokines and MetS (Figure 3B) showed that subjects with low (adipokines level lower than median) anti-inflammatory adipokines profile (18.9\%) has higher tendency of MetS prevalence $(\mathrm{OR}=1.38$; $\mathrm{p}$ $=0,22$ ) compare to subjects with high anti-inflammatory adipokines (13.7\%),

A study by Cawthorn et al. indicated that antiinflammatory adipokines may play a stronger role in regulating the adipokines, meaning that poor antiinflammatory adipokines level has a higher risk for increased incidence of MetS.
From the single adipokine crosstabulation analysis, we found that RBP4 and adiponectin had the best correlation with MetS as compared to other adipokines. Adiponectin is the most abundant adipokine in the plasma and has the strongest antiinflammatory properties. Adiponectin and RBP4 have an inversely mechanism via PPAR- $\gamma$ $(19,20)$. The crosstabulation analysis between adiponectin (represent the antiinflammatory adipokine) and RBP4 (represent the proinflammatory adipokine) showed that the prevalence of MetS became 1.49 times higher $(\mathrm{p}=0,24)$ when we combined the high RBP4 and low adiponectin profile $(21.1 \%)$, as compared to subjects with low RBP4 and high adiponectin (14\%) (group 1 vs 4).

Adiponectin seemed has a stronger role to the prevalence of MetS, showed by group 1 vs 2 in figure 4, where in the population with low levels of RBP4, decreased adiponectin levels caused increased MetS prevalence from $6.6 \%$ to $9 \%$, while in the population with high levels of adiponectin, increased RBP4 level only promoted MetS prevalence from $6.6 \%$ to $8.2 \%$ (group 1 vs 3 ), suggesting that high level of anti-inflammatory adipokine can give a protection to prevent MetS, even in the population with high proinflammatory adipokine level.

Table 2 showed that RBP4/Adiponectin ratio correlated significantly with the number of MetS components, positive correlation with TG and negatively correlated with HDL. 

Table 2. Correlation between RBP4/Adiponectin Ratio to the
Number of MetS Components

\begin{tabular}{lcc}
\hline Correlation & \multicolumn{2}{c}{ RBP4/Adiponectin Ration $(\mathbf{n}=\mathbf{1 2 2})$} \\
& $\mathbf{r}$ & $\mathbf{p}$ \\
\hline MetS Components & $0,20^{*}$ & 0,03 \\
FPG & 0,07 & 0,48 \\
SBP & 0,08 & 0,38 \\
DBP & 0,11 & 0,23 \\
TG & $0,26^{* *}$ & 0,00 \\
HDL & $-0 ., 11$ & 0.24 \\
\hline
\end{tabular}

Notes: FPG = Fasting Plasma Glucose; SBP = Systolic Blood Pressure; DBP $=$ Diastolic Blood Pressure; $\mathrm{HDL}=$ High Density Lipoprotein cholesterol; $r=$ Spearman correlation value; $p=$ significancy; * significant at $p<0,05 ;{ }^{\star \star}$ significant at $p<0,01$.

\section{Conclusions}

Overall, our in vitro study suggested that single inflammatory adipose tissue-induced factor might not influence MetS. Unlike in in vitro studies where we can control the environment, in our body adipose tissue activity is regulated dynamically in accordance with the integrated imbalance between whole body energy intake and energy expenditure. However, in an obesity scheme, more than a single factor will be resulted. Physiologically, our body system will compensate these factors. Problems may emerge when obesity continuously progresses, which tends to produce more and more inflammatory factors. These factors might not be compensated, which later will cause impairments of the body metabolism.

This study concerned only a small part of the pathogenesis of MetS. More adipokines will be revealed in the future that will bring us to a better understanding about the complexity of adipokines cross - communication and its effects on metabolism impairment.

\section{References:}

1. Asia Pasific Cohort Study Collaboration. The Burden of Overweight and Obesity in the Asia-Pasific Region. Obes Rev 2006; 8: 191-6.

2. Caballero AE. Endothelial Dysfunction in Obesity and Insulin Resistance: a Road to Diabetes and Heart Disease. Obes Res. 2003; 11: 1278-89.
3. Hotamisligil GS. Inflammation and Metabolic Disorders. Nature. 2006; 444: 860-7.

4. Van Gaal LF, Mertens IL, De Block CE. Mechanisms Linking Obesity with Cardiovascular Disease. Nature. 2006; 444 : 875-80.

5. Rosen ED, Spiegelman BM. Adipocyte as Regulators of Energy Balance and Glucose Homeostasis. Nature. 2006; 444 : 847-53.

6. Gong D, Yang R, Munir KM, Horenstein RB, Shuldiner AR. New Progress in Adipocytokine Research. Curr Opin Endo Diab. 2003; 10: 115-21.

7. Avogaro A, de Kreutzenberg SV. Mechanisms of Endothelial Dysfunction in Obesity. Clin Chim Acta. 2005; 360: 9-26.

8. Rana JS, Nieuwdorp M, Jukema JW, Kestelein JJP. Cardiovascular Metabolic Syndrome-An Interplay of Obesity, Inflammation, Diabetes and Coronary Heart Disease. Diabetes Obes Metab. 2007; 9: 218-32.

9. Bokarewa M, Nagaev I, Smith U, Tarkowski A. Resistin, an Adipocytokine with Potent Proinflamatory Properties. J Immunol. 2005; 174: 5789-95.

10. De Winther MPJ, Kanters E, Kraal G, Hofker MH. Nuclear Factor $\kappa \beta$ Signalling in Atherogenesis. Arterioscler Thromb Vasc Biol. 2005; 25 : 904-14.

11. Choi SH, Kwak SH, Youn BS, Lim S, Park YJ, Lee H, et al. High Plasma Retinol Binding Protein-4 and Low Plasma Adiponectin Concentrations Are Associated with Severity of Glucose Intolerance in Women with Previous Gestational Diabetes Mellitus. J Clin Endocrinol Metab. 2008; 93: 3142-8.

12. Aeberli I, Biebinger R, Lehmann R, l'Allemand D, Spinas GA, Zimmemann MB. Serum Retinol-Binding Protein 4 Concentration and Its Ratio to Serum Retinol Are Associated with Obesity and Metabolic Syndrome Components in Children. J Clin Endocrinol Metab 2007; 92: 4359-65.

13. Yao-BorengasserA, Varma V, Bodles AM, Rasouli N, Phanavanh $\mathrm{B}$, Lee MJ, et al. Retinol Binding Protein 4 Expression in Humans: Relationship to Insulin Resistance, Inflammation, and Response to Pioglitazone. J Clin Endocrinol Metab 2007; 92: 2590-7.

14. Meier $U$ and Gressner M. Endocrine Regulation of Energy Metabolism: Review of Pathobiochemical and Clinical 
Chemical Aspects of Vaspin, Ghrelin, Adiponectin, and Resistin. Clin Chem. 2004; 50: 1511-25.

15. Hida K, Wada J, Eguchi J, Zhang H, Baba M, Seida A, et al. Visceral adipose tissue-derived serine protease inhibitor: a unique insulin-sensitizing adipocytokine in obesity. Proc Natl Acad Sci USA 2005; 26: 10610-5.

17. Fantuzi G. Adipose Tissue, Adipokines, and Inflammation. J Allergy Clin Immunol. 2005; 115: 011-999

18 Frayn KN, Karpe F, Fielding BA, Macdonald IA, Coppack SW. Integrative physiology of human adipose tissue. Int $\mathrm{J}$ Obes Relat Metab Disord. 2003; 27: 875-88.
19. Cawthorn WP, Sethi JK. TNF- $\alpha$ and adipocyte biology. FEBS Lett. 2008; 582: 117-31

20 Mercarder J, Granados B, Bonet ML, Palou A. All-Trans Retinoic Acid Decreases Murine Adipose Retinol Binding Protein 4 Production. Cell Physiol Biochem 2008; 22: 363 -72.

21. Michalik L, Auwerx J, Berger JP, Chatterjee VK, Glass CK, Gonzalez FJ, et al. International Union of Pharmacology. LXI. Peroxisome proliferator-activated receptors. Pharmacol Rev 2006; 58: 726-41. 